\title{
Roma: capital de un Imperio bajo el signo de la biología política (1936-1942)
}

\author{
Gustavo Vallejo (*) \\ $\left({ }^{*}\right) \quad$ IIB-INTECH/CONICET-UNSAM. Chascomús, Buenos Aires. \\ gvallejo@intech.gov.ar
}

Dynamis

[0211-9536] 2012; $32(1): 115-140$
Fecha de recepción: 27 de julio de 2011

Fecha de aceptación: 14 de septiembre de 2011

SUMARIO: 1.-Roma entre la defensa social y la defensa de la raza. 2. - De la «mala vida» a la «biología política». 3.-La Roma antigua y la nueva Italia fascista. 4.-Epifanía de la Roma Imperial: defensa de la raza y la exposición E42. 5.-Principio del fin: «los italianos no son romanos».

RESUMEN: El trabajo interpela la construcción simbólica de Roma y la romanidad como factores de afirmación del poder del fascismo, especialmente luego de proclamarse la creación del Imperio en 1936. Dentro de ese marco, se indaga el papel jugado por la ciencia al legitimar la directa correlación de aquel universo simbólico con una praxis que exaltaba la superioridad racial atribuida a los herederos de una Roma milenaria. Se buscan así las articulaciones que presenta el discurso eugénico con el ejercicio del poder, al sostener científicamente una «biología política» en la que estaba inmerso el racismo fascista. Roma era la esencia de un Imperio que renacía después de quince siglos y entre su legado histórico y los nuevos escenarios creados por el fascismo para disciplinar la población, se tramaban las valencias de una romanidad que condensaba todas las virtudes de la raza. Esta última noción demostraría ser capaz de impulsar conquistas militares y a la vez suscitar una responsabilidad en la custodia de su estipe, instando a evitar «mestizajes indeseados» con los pueblos conquistados. Luego también propiciaría la prolongación de persecuciones a judíos iniciadas en Alemania. La ciencia participaba así de una extendida idea de hacer de la romanización, una cruzada en pos de imponer una fuerza sobrevalorada por fundamentaciones raciales que integraban la confianza depositada en el factor ambiental a un crudo determinismo biológico.

PALABRAS CLAVE: Roma, fascismo, raza, eugenesia, biotipología, biología política.

KEY WORDS: Rome, fascism, race, eugenics, biotypology, political biology. 


\section{Roma entre la defensa social y la defensa de la raza $\left(^{*}\right)$}

En 1936, tras siete meses de combate, Italia terminó de imponer una clara supremacía militar en África Oriental y Etiopía fue anexada a sus dominios. La lucha concluyó el 5 de mayo con la entrada del mariscal Badoglio en Addis Abeba, la capital etíope, y cuatro días más tarde el Duce proclamó la instauración de un nuevo Imperio, «el Imperio fascista que porta las señas indestructibles de la voluntad y de la potencia del Littorio Romano» ${ }^{1}$. El episodio militar derivaba así en una exaltación de los objetivos perseguidos por un régimen que hallaba la oportunidad para aunar el discurso con la praxis, el anhelo con la realidad: Roma volvía a ser la capital de un Imperio.

Las protestas internacionales tuvieron un tenor leve y culminaron cuando se hizo efectiva la toma de posesión de los territorios conquistados en una tácita aceptación de que una vez más se había cumplido la sentencia darwiniana y el pueblo «inferior» quedaba a merced del pueblo que había impuesto su superioridad en la «lucha por la vida».

Roma, el Littorio y el Imperio, vibraban en la palabra del Duce para dar lugar a una realidad largamente esperada. Ya en 1918 Mussolini expuso las ambiciones imperiales y el deseo de controlar el Mediterráneo para que Roma volviera a ser el faro de la civilización mundial ${ }^{2}$. Así, el fascismo descubrió en el mito de la romanidad un verdadero motor en la búsqueda de un destino que, como creía, estaba forjado en la historia. En 1921, el Duce decía:

«es el destino que el Mediterráneo vuelva a ser nuestro. Es el destino que Roma vuelva a ser la ciudad directriz de la civilización en todo el Occidente de Europa. Levantamos la bandera del imperio, de nuestro imperialismo, que no debe ser confundido con aquellos de marca prusiana o inglesa» ${ }^{3}$.

La construcción simbólica de la romanidad fue acompañada de transformaciones urbanas llevadas a cabo por el fascismo en un breve lapso. Un lugar preponderante lo ocuparon indagaciones arqueológicas que precedieron la tarea dirigida a recuperar la Roma antigua, a partir de grandes demoliciones con las que fueron aislados los monumentos clásicos. También

(*) Este trabajo forma parte de tareas enmarcadas en el PIP CONICET 114-200801-00258 y en PICT ANPCYT 01559-2007, ambos con sede en el IIB-INTECH/CONICET-UNSAM.

1. Mussolini, Benito. La conquista dell' Etiopia. Bari: Editore Pasquale di Canosa; 1936, p. 10.

2. Gentile, Emilio. Fascismo di pietra. Bari: Laterza; 2010, p. 41.

3. Reproducido en Gentile, n. 2, p. 47. 
se trazaron amplias vías para conectar esos monumentos y a la vez realizar multitudinarias concentraciones. Las intervenciones urbanas estuvieron acompañadas de una verdadera explosión demográfica: la proclamación del Imperio encontraba a su capital, en 1936, con 1.179.037 habitantes, siendo la ciudad más poblada de Italia. Desde 1921 su población había crecido un $74 \%$ mientras que Milán lo había hecho un 36\%. Además del aumento en la natalidad, fuertes migraciones internas atraídas por la obra pública ocasionaron la llegada a Roma de unas 800.000 personas desde el ascenso del Duce 4 . Al mismo tiempo y a consecuencia de esa misma «fascistización del espacio» que implicó liberar monumentos y abrir arterias a expensas de realizar grandes demoliciones, 150.000 romanos pertenecientes a sectores populares debieron abandonar el centro para dirigirse a la periferia. Sobre ellos el fascismo desplegó su acción asistencial para contener los «problemas de la necesidad» construyendo escuelas, casas, hospitales, centros educativos y deportivos.

El crecimiento de Roma se había producido mientras el propio Mussolini impulsaba una fuerte campaña contra el urbanismo, al considerarlo un fenómeno que «minaba la sanidad de la estirpe». Estas coordenadas ideológicas se ensamblaban con un discurso científico que acompañó decididamente una cruzada poblacionista del régimen que iba en paralelo con estímulos para la radicación en el contexto rural. Sin embargo, Roma constituía un caso especial y a diferencia de la tendencia aplicada al resto de Italia, allí el crecimiento de la población urbana era entendido como un signo de vitalidad del Imperio y la cultura latina. A Roma se le atribuía la continuidad de un pasado glorioso a través de una tradición que iluminaba la acción política, por haber mantenido una verdadera «raza». Custodiarla e impulsar su crecimiento era un mandato de aquello que en definitiva fue un poblacionismo, pero de tipo «selectivo» ${ }^{5}$.

Entre la conquista militar y la exaltación del mito de Roma quedaba en evidencia que el uso explícito de la fuerza era tan importante como la función legitimadora que tenía la creación de un universo simbólico, donde la sacralización de la política se valía también de los aportes del campo científico. Ya sea para construir discursos historiográficos susceptibles

\footnotetext{
4. Gentile, n. 2, p. 108.

5. El concepto de «poblacionismo selectivo», aplicado a una matriz italiana fuertemente influyente en realidades latinoamericanas, fue acuñado en Miranda, Marisa. La biotipología en el pronatalismo argentino (1930-1983). Asclepio. 2005; 57 (1): 189-218.
} 
de transformarse en plataformas de acción política, o bien para sentar las bases de teorías que fundamentaban la superioridad racial de los que estaban llamados a vencer en la «lucha por la vida» por ser portadores de la tradición milenaria de una ciudad.

Vale decir que dentro de una economía del poder que instaba a equilibrar las relaciones entre violencia y consenso, el disciplinamiento interior se reforzaba con la colonización de territorios extranjeros. Para el fascismo la guerra era su fuente de origen y un fundamento constitutivo que necesitaba ser permanentemente reactualizado. Giuseppe Bottai escribía en 1932 que el fascismo «no era, para mis compañeros y para mí, más que un modo de continuar la guerra, de traducir sus valores en una religión civil» ${ }^{6}$. Así se invertía la conocida sentencia de Karl von Clausewitz en un régimen para el que la política era la continuación de la guerra a través de otros medios $^{7}$, inscribiéndose de manera permanente en las nuevas instituciones. Primero fue la lucha mantenida contra los «enemigos internos» y la antigua clase dirigente, para poner en práctica la unidad moral y espiritual de la nueva Italia ${ }^{8}$ que era también una unidad racial construida cultural y científicamente. Y cuando ese frente pareció quedar «inmunizado» ${ }^{9}$ la lucha fue declarada contra otras razas que se habían infiltrado o podrían llegar a hacerlo.

Está claro que la noción de «lucha», aplicada al problema racial, se entroncaba directamente con el desarrollo internacional de la eugenesia ${ }^{10}$, que, desde el Congreso celebrado en Londres en 1912 desató un movimiento de escala planetaria. Dentro de ese marco Italia gestó una eugenesia con

6. Reproducido por Gentile, n. 2, p. 45.

7. Para von Clausewitz, la guerra era «la continuación de la política a través de otros medios». Carl von Clausewitz. De la guerra, Barcelona: Labor; 1984 [la primera edición alemana es de 1832].

8. Gentile, n. 2, p. 45.

9. Espósito asocia el concepto foucaultiano de «biopolítica» al de «inmunidad», como forma de evitar el contagio de seres superiores por seres inferiores, que advierte particularmente en el discurso y la praxis del nazismo. Véase Espósito, Roberto. Comunidad, inmunidad y biopolítica. Barcelona: Herder; 2009, p. 141-154.

10. La relación entre el concepto de «lucha» y la eugenesia se hizo por demás explícita en Alemania. Allí la expresión darwiniana struggle for life - a la que Darwin había dado un amplio, aunque problemático sentido metafórico - fue traducida de por el vocablo Kampf, que sugiere agresión y guerra al pie de la letra (de ahí Mein Kampf —Mi Lucha一). Girón, Álvaro. Darwinismo, darwinismo social e izquierda política (1859-1914). In: Miranda, Marisa; Vallejo, Gustavo, eds. Darwinismo social y eugenesia en el mundo latino. Buenos Aires: Siglo XXI Iberoamericana; 2005, p. 23-58 (48). 
características propias que se ensamblaban a su vez con los elementos centrales de la romanidad mussoliniana. Así, si la defensa social fue inherente a la instalación del régimen, la noción de defensa de la raza, será después de la conquista de Etiopía una solución planteada para que la cohesión alcanzada quedara a salvo de «infiltraciones indeseadas». Entre ambas instancias biopolíticas se situaba Roma y el desplazamiento de una mirada científica que se posó en ella primero para inducir a su regeneración y luego para proveer de insumos teóricos en la tarea de proteger la «estirpe» y con su ejemplo romanizar Italia. Nuestro trabajo así busca dar cuenta del papel que cumplieron constructos científicos ante el avance de la romanización, entendida como una cruzada eugénica en pos de imponer una fuerza sobrevalorada por fundamentaciones raciales que integraban la confianza depositada en el factor ambiental a un crudo determinismo biológico.

\section{De la «mala vida» a la «biología política»}

Antes de producirse el ascenso del Duce, Roma había sido objeto de estudio para un campo científico que generó, con la figura de la «mala vida», un modelo de criminalización de lo «anormal» en la ciudad moderna, creado por Alfredo Nicéforo y Scipio Sighele y propagado internacionalmente ${ }^{11}$.

La Roma de la «mala vida» sería la contracara que necesitó el fascismo para afianzar sobre ella el mito de la romanidad, como una alternativa al presente a través de un salto al pasado y al futuro. La «mala vida», en tanto reacción ante fenómenos acaecidos por el urbanismo que alteraba el orden

11. Niceforo, Alfredo; Scipio, Sighele. La mala vita a Roma. Turin: RouxFrasati; 1898. Sobre la «mala vida» y su propagación internacional véase Huertas, Rafael. El delincuente y su patología. Medicina, crimen y sociedad en el positivismo argentino. Madrid: CSIC; 1991; Campos Marín, Ricardo. Los fronterizos del delito. Las relaciones entre crimen y mala vida en España y Argentina a comienzos del siglo XX. In: Miranda, Marisa; Girón Sierra, Álvaro, coords. Cuerpo, biopolítica y control social: Latinoamérica y Europa en los siglos XIX y XX. Buenos Aires: Siglo XXI Iberoamericana; 2009, p. 115-137. La «mala vida» fue abordada en un monográfico del Journal of Spanish Cultural Studies. 200910 (4). Entre los trabajos incluidos se hallan los de Cleminson, Richard; Fuentes Peris, Teresa. La «mala vida»: source and focus of degeneration, degeneracy and decline, p. 385-397; Campos, Ricardo. La clasificación de lo difuso: El concepto de «mala vida» en la literatura criminológica de cambio de siglo, p. 399-422; Huertas, Rafael. Los niños de la «mala vida»: la patología del «golfo» en la España de entresiglos, p. 423-440; Cleminson, Richard. Transnational discourse on the «mala vida», male homosexuality in Madrid, Buenos Aires and Barcelona: p. 461-483. 
social, fue también un anticipo del desarrollo de la eugenesia, cuyo puente con la escuela positiva lombrosiana ${ }^{12}$ se empeñaron en tenderlo figuras como el propio Nicéforo.

La Gran Guerra acrecentó el pesimismo sobre la condición urbana, para convertirla en una demostración palpable del avance de la degeneración en todas sus formas ${ }^{13}$. Roma era para Mussolini, la «puerca Roma»,

«ciudad vieja, estrecha y provincial, un gran burgo, capital modesta de un reino modesto, notorio centro burocrático de corrupción de la Italia liberal y parlamentaria, meta de peregrinaciones y de caravanas turísticas servilmente recibidas por una población de hoteleros, comerciantes, vendedores ambulantes, lustrabotas y cantantes de baladas» ${ }^{14}$.

Desde esta perspectiva, Roma estaba afectada por la desidia con la que burgueses y monárquicos toleraron su pasiva adaptación a las funciones que imponía la sociedad moderna. Esa Roma sería el punto de partida, el inicio de un camino hacia su regeneración, algo que el fascismo impulsaba para conseguir a través de ese medio la regeneración de Italia. Mussolini quería transformar la ciudad para convertirla en la gran capital moderna de una Roma imperial. «Pensamos hacer de Roma la ciudad de nuestro espíritu»,

«una ciudad depurada, desinfectada de todos los elementos que la corrompen y la manchan, pensamos hacer de Roma el corazón pulsante, el espíritu presto de la Italia imperial que nosotros soñamos» ${ }^{15}$.

En la voz del Duce, las metáforas médicas abrían paso a la instauración de una biopolítica que asumiría la forma de una «biología política», y en la

12. Sobre el tema es indispensable ver a Peset, José; Peset, Mariano. Lombroso y la escuela positivista italiana. Madrid: CSIC; 1975 y la obra colectiva Montaldo, Silvano; Trappero, Paolo, eds. Cesare Lombroso. Centoanni dopo. Torino: UTET; 2009.

13. Sobre la propagación del degeneracionismo, iniciado con Morel a mediados del siglo XIX, véase Pick, Daniel. Faces of degeneration. A European disorders, c. 1848-c. 1918, Cambridge: Cambridge University Press; 1989. Campos Marín, Ricardo; Martínez Pérez, José; Huertas García Alejo, Rafael. Los ilegales de la naturaleza. Medicina y degeneracionismo en la España de la Restauración (1876-1923). Madrid: CSIC; 2000; Girón Sierra, Álvaro. Metáforas finiseculares del declive biológico: degeneración y revolución en el anarquismo español, Asclepio. 1999: 51 (1): 247-273. Para el caso italiano: Gervasoni, Marco. Cultura della degenerazione'tra socialismo e criminologiaalla fine dell'Ottocento in Italia. Studi Storici. 1997: 38 (4): 1087-1119.

14. Gentile, n. 2, p. 235.

15. Gentile, n. 2, p. 64. 
que el enfermo era el pueblo, en su conjunto, demandante de una asepsia que eliminara las causas de la «degeneración». El Imperio anhelado exigía asegurar la salud de su capital apelando al pasado y al futuro, a la antigua Roma vigorosa y la nueva Italia regenerada. De ese modo, degeneración y regeneración conformarán un par dialógico fundamental para la organización discursiva del fascismo.

Sobre este sustrato, la Gran Guerra y sus consecuencias desatarán una fuerte avidez por comprender la realidad desde un prisma eugénico. En plena posguerra el campo eugénico italiano estaba claramente conformado y por su intermedio se instaló el debate en torno a los beneficios raciales de la contienda al haber eliminado a los «más débiles» en el campo de batalla. Desde la Sociedad Italiana de Genética y Eugenesia (SIGE), dirigida por Corrado Gini, podía considerarse la guerra como un eficaz medio regenerador que favorecía la reconstrucción del Estado italiano a partir de la definitiva eliminación de los conceptos de caridad y beneficencia y a su vez instaba a la protección de la raza victoriosa en la contienda. Estas ideas derivaron en la elaboración de un documento que en agosto de 1919 el propio Gini envió a Leonard Darwin, hijo de Charles y organizador del 1 . ${ }^{\text {er }}$ Congreso de Eugenesia en Londres. En él, abogaba por una legislación que impidiera en toda Europa eventuales uniones matrimoniales con razas africanas. El documento había sido elaborado por Vicenzo Giuffrida Ruggeri en el seno de la SIGE ${ }^{16}$.

La «Marcha sobre Roma», entonces, coincidió con el intento de sistematizar inquietudes eugénicas exaltadas por la guerra y que retomaban en Italia la impronta dejada por saberes normativos que desde fines del siglo XIX contribuyeron a proyectar los alcances de la medicina y el derecho a vastos campos de la esfera social ${ }^{17}$. En 1922 apareció la revista Difesa Sociale cuando ya Nicola Pende había anticipado sus investigaciones en biotipología, verdadero germen de una versión italiana de la eugenesia diseñada a la medida de las necesidades que imponía la política del fascismo ${ }^{18}$. En

16. Cassata, Francesco. Molti, sani e forti. L'eugenetica in Italia. Torino: Bollati Boringhieri; 2006, p. 77.

17. Los saberes normativos son aquellos que se asocian a las funciones disciplinarias que tuvieron en distintos momentos históricos, la Medicina, el Derecho y la Teología, para distinguir qué es sano o normal de lo patológico o anormal. Huertas, Rafael. Los laboratorios de la norma, Madrid: Octaedro-CSIC; 2008.

18. En momentos previos a la «Marcha sobre Roma» aparecieron: Pende, Nicola. Della medicina alla sociologia. Prometeo: Palermo; 1921. Pende, Nicola. La debolezze di costituzione. Introduzione 
1923 Difesa Sociale publicó el proyecto de Pende de crear un instituto para el estudio del crecimiento, de la biología y psicología del individuo y de la raza. Sería un centro para recabar la información física, psíquica, moral, de cada miembro de la población, que quedaría concentrada en un sistema de fichas biotipológicas. El fin último era lograr que esta estructura inscrita en el escenario urbano pudiera irradiarse capilarmente sobre diversas ciudades, cada una de las cuales tendrían en el instituto biotipológico el archivo médico-genealógico-estadístico de cada uno de todos sus habitantes. La idea de ejercer desde la ciudad el control individualizado y totalizante de las poblaciones para asegurar la gobernabilidad, detectando anomalías físicas y/o morales en seres «aparentemente sanos», fue fundamental para emprender la tarea de «detectar» el «justo lugar» que le correspondía ocupar a cada célula del organismo social y cerciorarse de su disciplinado acatamiento del orden establecido. Se trataba de un programa que Pende llamó de «biología política», consistiendo en una respuesta científica para garantizar el control sanitario, político y moral de las poblaciones ${ }^{19}$.

En 1926 Pende pudo ver plasmado su proyecto con la inauguración del primer Instituto Biotipológico. El poder de Pende dentro del régimen fue en ascenso hasta acceder al cargo de Senador, integrando la intensa propaganda de la obra del fascismo que poblaba un nuevo medio, el film, a través de cortometrajes que realizaba el Instituto LUCE (La Unión Cinematográfica Educativa).

Las clasificaciones de Pende, resultaron de gran utilidad para ser proyectadas sobre el universo de jóvenes escolarizados que eran objeto de las acciones asistenciales llevadas a cabo por dos instituciones centrales del

alla patología costituzionale. Roma: G. Bardi; 1922. Nicola Pende (1880-1970), fue una reconocida figura del campo médico y social en la Italia de la primera mitad del siglo XX. Se formó en la escuela constitucionalista de Giacinto Viola, afirmando una orientación interesada en integrar preceptos clásicos y religiosos a saberes modernos. Realizó sus primeros estudios en endocrinología clínica y experimental, antes de formular su teoría biotipológica. Sobre Pende puede verse en la compilación de Miranda, Marisa; Vallejo, Gustavo, eds. Darwinismo social y eugenesia en el mundo latino. Buenos Aires: Siglo XXI Iberoamericana; 2005, los capítulos de Galera, Andrés. Hacia una fisiología del delito: el modelo biotipológico de Nicola Pende, p. 363-374, y de Vallejo, Gustavo. Las formas del organicismo social en la eugenesia latina, p. 231-272. Véase además Cassata, n. 16, p. 188-219.

19. Sobre los institutos biotipológicos véase: Vallejo, Gustavo. El ojo del poder en el espacio del saber: los institutos de biotipología. Asclepio. 2004; 56 (1): 219-244. 
fascismo, nacidas también en 1926: la Opera Nazionale per la Maternità e l'Infanzia (OMNI) y la Opera Nazionale Balilla ${ }^{20}$ (ONB).

En Roma, la OMNI pasó a funcionar bajo la dirección de Sante De Santis, psicólogo formado en la escuela constitucionalista que sirvió de principal precedente a la biotipología. En ese rol De Santis afianzó las relaciones entre la política asistencial fascista y la «defensa de la estirpe», considerando como un problema central la distinción entre «recuperables» $\mathrm{y}$ «rechazados» ${ }^{21}$, dado que la intervención de la OMNI sólo se justificaba si era en «favor de aquellos individuos que son reconocidos como elementos útiles y productivos para la nación» ${ }^{22}$.

El fascismo articulaba desde la preponderante orientación eugénica que imponía la «biología política», una ecuación constante entre costos y beneficios, por el asistencialismo o el antiasistencialismo, que según el caso debía impulsar cada institución encargada de proteger la estirpe.

Por su parte la ONB, dirigida por Renato Ricci, requería también de los exámenes biotipológicos. La ONB fue creada para organizar el tiempo libre de niños y jóvenes, introduciéndolos en el universo de mitos y ritos fascistas a través de la actividad física militarizada. Estaba articulada a través de dos formaciones principales: las Balillas propiamente, para aquellos que tenían de 6 a 14 años y los Vanguardistas, para quienes tenían entre 14 y 18 años.

Pero la contribución de Pende el Estado corporativo no se limitaría a establecer un sistema clasificatorio para precisar los alcances del asistencialismo fascista. Por sobre todas las cosas, proporcionaría sustento científico a la noción de «biología política» a través de una teoría que integró el vi-

20. Balilla proviene del presunto sobrenombre de un joven que en la Génova de 1746 inició la revuelta antiaustríaca. En torno al Resorgimento deviene en símbolo duradero de heroísmo infantil y patriotismo popular y es reapropiado por el fascismo al identificarse con ese símbolo a un joven en los prolegómenos de la «Marcha sobre Roma». Gibelli, Antonio. Opera Nazionale Balilla. In: De Grazia, Victoria; Luzzatto, Sergio, eds. Dizionario del fascismo. Tomo II. L-Z. Torino: Einaudi; 2005, p. 267-271(267).

21. Decía De Santis: «Al grupo "rechazado" debemos asignar los menores deficientes, paralíticos, graves o del tipo idiota, los deficientes, epilépticos graves, los inválidos complicados, tales como: sordomudos o ciegos deficientes, o ciegos-epilépticos, o los inválidos mentales con tuberculosis. Al grupo "recuperable" se le asignará fácilmente los menores llamados "diferenciados" y los deficientes y los epilépticos paréticos o no, pero no muy graves, y los inestables de especie variada (...). La asistencia técnica de los "recuperables" se hace, porque (diciéndolo en términos bancarios, tan brutales) lo que se gasta es una especie de anticipo o préstamo de la comunidad, que el futuro desempeño del asistido compensará a su tiempo». Cassata, n. 16, p. 137.

22. Reproducido en Casatta, n. 16, p. 138. 
talismo biológico y habilitó la paralela articulación entre ciencia y religión. Esta perspectiva se valía de la metáfora del cuerpo social conformado por órganos superiores e inferiores, sanos y enfermos, para propender diferencialmente la reproducción de unos en detrimento de otros. El fundamento darwinista era trastocado al aplicarse al plano social eliminando su componente azaroso. La imprevisibilidad de la «lucha» dejaba paso a la utopía planificadora de un biológico orden finalista.

La teoría orgánica exaltaba la correspondencia que existía entre el Estado corporativo y los fundamentos biológicos de la Biotipología. Desde su óptica, el paso del darwinismo social de regímenes ultraliberales al fascismo, venía signado por un equivalente desplazamiento de un enfoque biológico que entendía el organismo como el marco de una competencia interindividual generalizada hacia otro de corte vitalista que lo consideraba como el resultado de interacciones corporativas ${ }^{23}$. La sociedad nacional ideal era una meta que no podría plantearse, sino sobre la división corporativa de clases, complementada con el rol armonizador de un Estado fuerte, «unitario y unificador», contraparte social de la biología totalizadora del individuo.

La Biotipología se proponía detectar predisposiciones morbosas, candidatos al delito o a enfermedades contagiosas, para aislar esa entidad amenazante antes que su mal «infectara» al resto del cuerpo social. Introduciéndose en lo profundo del ser a través de un desplazamiento de la antropología física a la endócrina, buscaba detectar «alteraciones individuales» de tipo hormonal y moral capaces de transmitirse a la esfera social.

Pero a su vez, si el Estado corporativo fascista era la expresión de un sistema político verdaderamente biológico, donde prevalecía la unidad de lo múltiple y las desigualdades sociales eran naturalizadas al quedar parangonadas a las que existen entre los distintos tipos de células y tejidos que componen el organismo, la organización física del territorio también debía reflejar la misma orientación. Eso pensaba en 1935 el urbanista Alberto Sartoris, para quien cada ciudad debía cumplir una precisa función dentro del organismo social. De ahí provino la noción de "ciudad corporativa», inherente al establecimiento de «una economía controlada y organizada» que define «el deber productivo de la ciudad» y consecuentemente su tamaño. Cada ciudad estaba sujeta a una estrategia que integraba las variables de calidad y cantidad — problema central de la eugenesia-, a través de la pre- 
figuración de sus formas físicas (con un sentido funcional) y su capacidad poblacional, establecidas por un plan regulador ${ }^{24}$.

La «ciudad corporativa» canalizaba una precisa delimitación doctrinaria que Giuseppe Bottai estableció prolongando la biologización del Estado corporativo a la nueva disciplina para el ordenamiento del territorio: «el urbanismo está en la urbs como la tisis en el cuerpo sano del hombre; pero la urbanística está en el urbanismo, como la tisiología está en tisis» ${ }^{25}$. La ciencia era el vínculo de una estrategia que unía la indagación de la ciudad en general como la del hombre sano individualmente para operar, invirtiendo la consideración de la anormalidad como una anomalía, sobre la presunción constante de la existencia del mal hasta tanto pudiera comprobarse el estado de normalidad. Desde esta perspectiva medicalizadora, el mal per se identificado en el urbanismo, dejaba en pie su cura residente en la urbanística, la cual podía ser entendida como instrumento para la organización de las poblaciones en función de las necesidades que establecía el cuerpo social. Y a su vez, instalaba la certeza de que, dentro de un organismo, integrado poblacionalmente por individuos y territorialmente por ciudades, a Roma le cabía cumplir una misión directiva como lo hace la cabeza ordenando las tareas de las extremidades.

\section{La Roma antigua y la nueva Italia fascista}

Para cumplir la función que le demandaba el cuerpo social a Roma, el fascismo construyó un universo de símbolos asociados a esa ciudad. Comenzó instaurando como fiesta nacional el nacimiento de Roma, que para Mussolini significaba «celebrar nuestro tipo de civilización», «exaltar nuestra historia y nuestra raza» ${ }^{26}$. También buscó crear una nueva tradición y el calendario adoptó otra fecha de Roma, en este caso la de la propia «Marcha sobre Roma», para indicar con ese episodio el inicio de una nueva era fascista adoptado el modelo de la era cristiana.

En la búsqueda de amalgamar el pasado clásico y el futuro fascista, las aportaciones provenientes de la arqueología se conjugaban con las de la

\footnotetext{
24. Sartoris, Alberto. La ciudad corporativa. Revista de Administración Municipal. 1935: 3-15 (14).

25. Reproducido en Finotto, Francesco. La città aperta. Storia delle teorie urbanistiche moderne. Venezia: Marzilio Editori; 2001, p. 23.

26. Succimarra, Luca. Natale di Roma. In: De Grazia; Luzzatto, n. 20, p. 207.
} 
arquitectura, para llevar a cabo una escenificación de lo que sería el nuevo imperio sobre la base de lo que había sido el antiguo imperio romano.

Una de las acciones arqueológicas impulsadas tuvo que ver con los homenajes tributados a Augusto, honrado en su condición de primer emperador romano. En 1926 el arqueólogo G. Giglioti comenzó a trabajar en el mausoleo, unas enormes ruinas circulares situadas cerca del río Tíber, en una zona muy deteriorada ${ }^{27}$, para las que se requirieron grandes demoliciones hasta dejar aislado el yacimiento. Luego se dio inicio a un plan general, a cargo del arquitecto Del Debbio, que se prolongó en el tiempo bajo un insistente impulso de Mussolini, en su afán por mostrarse como el nuevo Augusto.

Al mismo tiempo comenzaron otros emprendimientos de gran significación. En 1932 con el decenio del ascenso al poder de Mussolini quedó inaugurado el Foro Mussolini, como también la Vía del Imperio y la Muestra de la Revolución Fascista, completándose un universo de símbolos que venían a reforzar las valencias atemporales atribuidas a Roma en directa vinculación con la eternización del Duce.

La Vía del Imperio, fue la operación urbanística más importante del primer decenio y con ella el fascismo celebró el triunfo de la Roma mussoliniana sobre la Roma Real. Así, a la conquista política, le sucedía una «conquista monumental» de Roma, mediante la «fascistización del espacio» ${ }^{28}$. Concebida como arteria moderna, la Vía del Imperio fue el principal lugar para el desfile de las Fuerzas Armadas y de las organizaciones del partido fascista.

Por su parte, la Muestra de la Revolución Fascista, fue montada en el Palacio de las Bellas Artes, un edificio neoclásico situado en la Vía Nazionale al que se le adosó una impactante fachada de casi 40 metros de altura, donde el gesto futurista se integraba a una arquitectura parlante concebida desde el racionalismo modernista (Figura 1). La Muestra fue inaugurada por Mussolini el 28 de octubre de 1932 y quedó abierta al público por dos años, recibiendo más de 2.800 .000 visitantes. Allí se presentaba al fascismo como una fuerza unificadora, destacando, en términos biomédicos, los resultados sanitarios en la lucha contra la tuberculosis, la mortalidad infantil y la

27. Benton, Tim. Roma reivindica l'imperi. In: Ades, Down; Benton, Tim; Elliott, David; Boyd White, lain, eds. Art i poder. L'Europa dels dictadors. 1930-1945. Barcelona: CCCB; 1990, p. 120-129 (121).

28. Gentile, n. 2, p. 89. 
«desinfección» operada tras eliminar al «bacilo socialista y comunista» ${ }^{29}$. Así y tras exaltar que la nación había sido salvada de «elementos subversivos», el mensaje instaba a las masas a ejercer una constante vigilancia para proteger las instituciones políticas, algo que en términos biopolíticos equivalía a preservar el estado de «inmunidad» alcanzado $^{30}$.

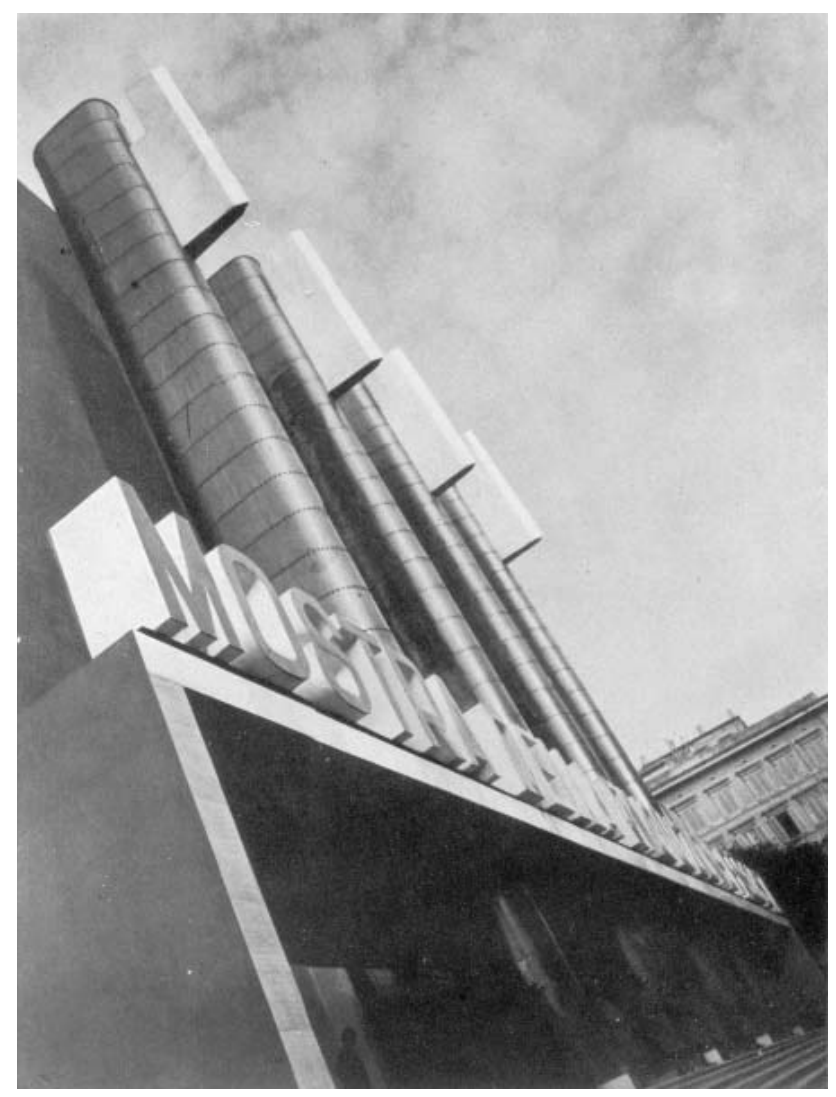

Figura 1. Fachada de la Muestra de la Revolución Fascista. Los cuatro elementos verticales realizados en acero y revestidos con láminas de cobre simbolizan el fasciolittorio con sus hachas. Fuente: Mostra della Rivoluzione Fascista in Roma. Rassegna di Archittetura. 1933; 7-8: 320-321.

29. Stone, Marla. Mostra della Rivoluzione Fascista. In: De Grazia, Victoria e Luzzatto, Sergio, eds. Dizionario del fascismo. Tomo I. A-K; Torino: Einaudi; 2005, p. 178-181(181).

30. Espósito, n. 9, p. 141-154. 
Pero además de estas iniciativas que exhibían de la manera más diáfana posible el poder del régimen, las celebraciones del decenio condujeron a la creación del Foro Mussolini, un escenario simbólico que a la vez planteaba novedosas articulaciones entre una Roma atemporal y las valencias atribuidas desde la «biología política» a la educación física (Figura 2). El Foro albergaba la ONB para favorecer la actividad física entre escolares

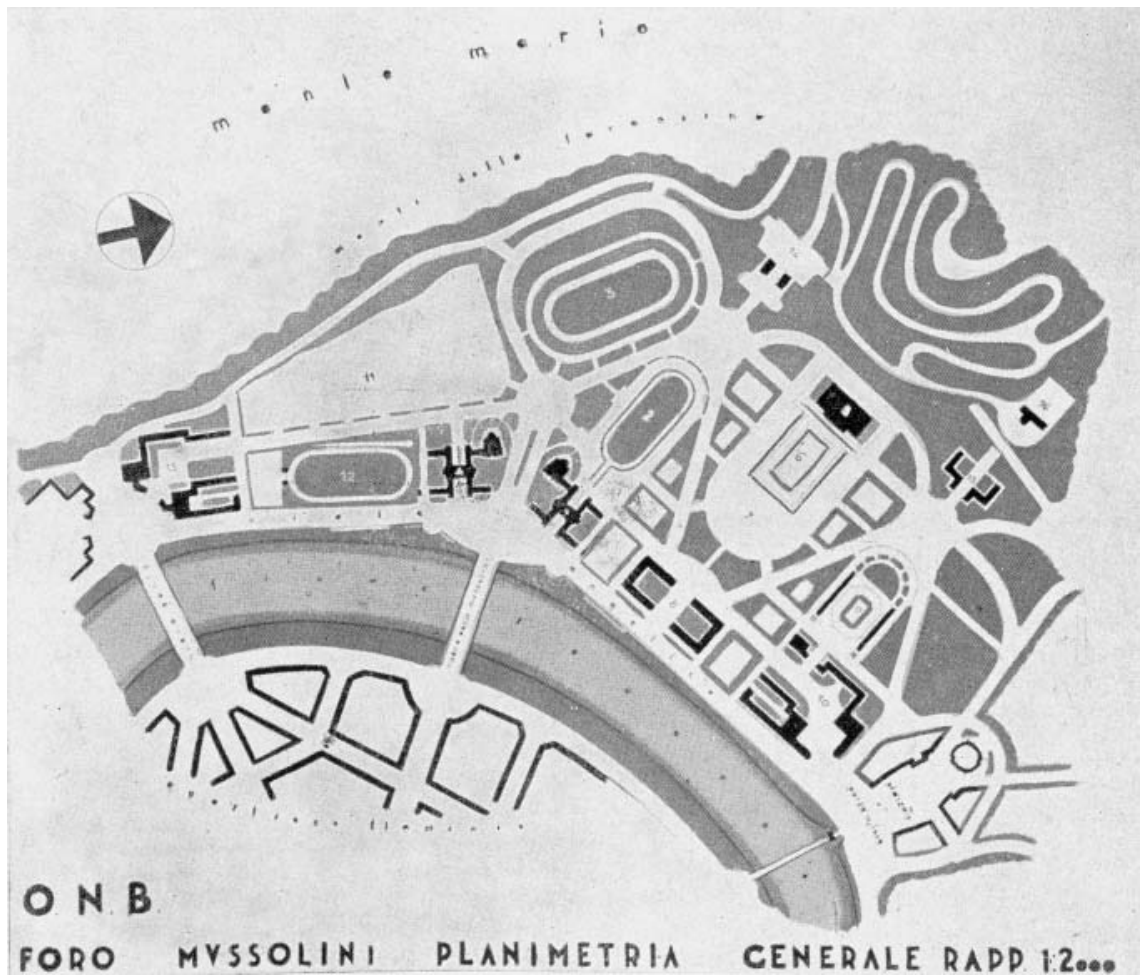

Figura 2. Planimetría general del Foro Mussolini. Fuente: II «Foro Mussolini» in Roma. Rassegna di Archittetura. 1933; 7-8: 324-328.

seleccionados biotipológicamente. Incluía el cuartel general para la élite de instructores de atletismo y el campo de actividades para todo el movimiento de la $\mathrm{ONB}$, ocupando una gran extensión sobre la ribera derecha del Tíber, al norte de la ciudad. Estaba comunicado con el casco antiguo a través del Puente Milvio y se situaba al pie del Monte Mario, lugar de gran 
belleza y fuerte valor sentimental: en ese sitio los «camisas negras» habían acampado durante la «Marcha sobre Roma» ${ }^{31}$.

El Foro Mussolini reunía así a las instituciones dedicadas a «formar física e ideológicamente los nuevos dirigentes de las organizaciones», y a crear «un monumento que, refiriéndose a la tradición imperial romana, perpetuara por los siglos el recuerdo de la nueva civilización fascista, ligándola al nombre de su líder» ${ }^{32}$. Con la ONB y el Foro Mussolini, la fascistización del espacio iniciada con la realización de la Via del Imperio era proseguida por la fascistización del deporte y el tiempo libre ${ }^{33}$ (Figura 3). La ONB promovía los valores clásicos del deporte no agonístico, que eran asociados a la idea de crear una población fuerte, de jóvenes sanos y robustos. En su implementación, pasó a ocupar todos los espacios de la educación extraescolar, controlando el tiempo libre de la infancia y la

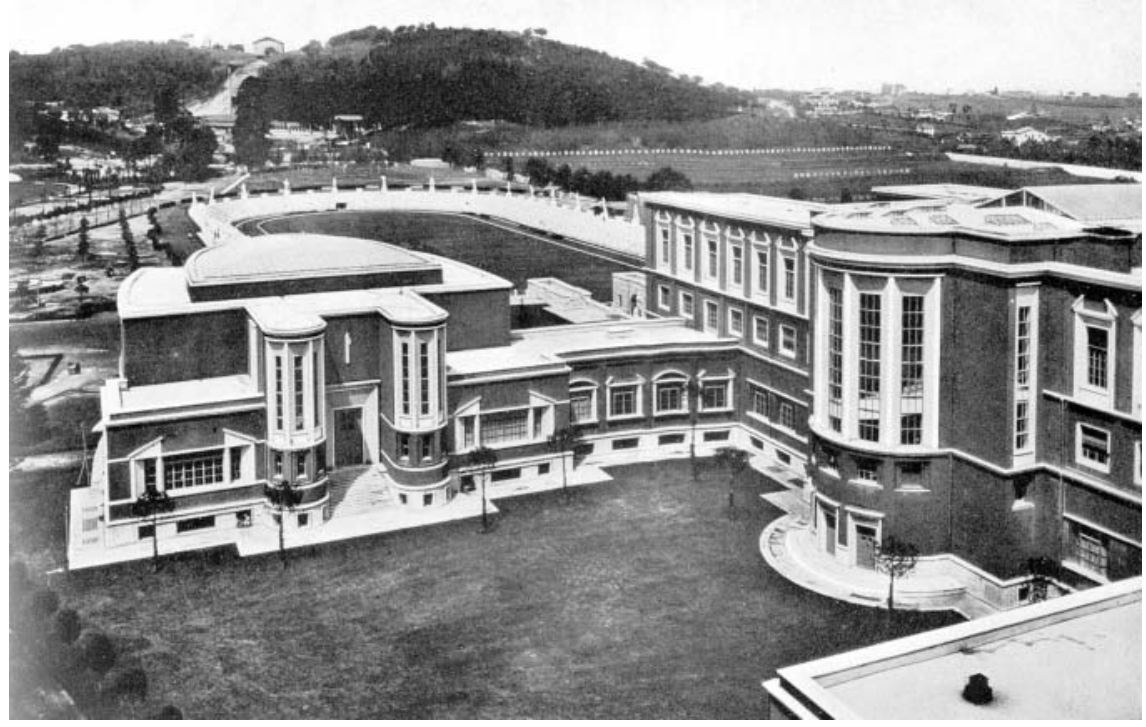

Figura 3. Vista de la Academia Fascista di Educazione Fisica y detrás el Estadio dei Marmi. Fuente: II «Foro Mussolini» in Roma. Rassegna di Archittetura. 1933; 7-8: 324-328.

31. Benton, n. 27, p. 125.

32. Gentile, n. 2, p. 99.

33. Lang, Peter. Foro Mussolini. In: De Grazia; Luzzatto, n. 29, p. 549-550 (549). 
adolescencia, inculcando la mentalidad y la ideología dominante a través de la educación física, la actividad deportiva y el adiestramiento militar ${ }^{34}$.

La biotipología formó parte de este campo de acción, el cual materializaba uno de sus propósitos fundantes, consistentes en impulsar la «educación física, moral e intelectual de la juventud» dentro de los patrones de la «biología política». Y si bien la comunión de intereses se remontaba a la casi simultánea inauguración del Instituto Biotipológico y la ONB; las celebraciones del decenio fascista llevaron a Pende a exaltar la correlación del organicismo de su teoría con las iniciativas del Estado fascista, enunciando el concepto de «totalitarismo biotipológico» como aplicación de la «biología política» ${ }^{35}$. Dentro de ese marco, la ONB expresaba la novedosa incorporación de la ciencia en la «tutela» de los escolares ${ }^{36}$.

Luego de la selección inicial, la biotipología aportaba exámenes clasificatorios de los que podían deducirse las aptitudes a una determinada actividad física, bajo la consigna de que la «biología política» atravesaba distintos planos del orden social: así como cada célula cumple su misión en el organismo, cada individuo debe ocupar el «justo lugar» que era detectado por la biotipología. La nueva educación física italiana requería así de fichajes orientados por el método VHARF, denominación conformada por las iniciales de Velocidad, Habilidad, Resistencia y Fuerza, las cuatro categorías básicas del desempeño físico que se correspondían con uno de los cuatro biotipos principales definidos por Pende. Estos fichajes que inicialmente participaron en la tarea básica de preparación para la futura actividad laboral, también se proyectaron hacia la específica preparación deportiva, como forma de llevar la competencia internacional también al terreno de los éxitos olímpicos. Así, con la ONB y la ciencia puesta a su servicio, el fascismo encontraría una pieza clave para afirmar la utilización política de la educación física y el deporte ${ }^{37}$, algo que no tenía antecedentes en otras naciones, aunque en poco tiempo asumiría un papel central en Alemania.

\footnotetext{
34. Gibelli, n. 20, p. 270.

35. Pende, Nicola. Bonifica umana razionale e biologia política. Bologna: Licinio Capelli; 1933.

36. «La Italia fascista en el campo de la educación física demuestra no querer ser segunda de ninguna otra nación, al dar esta orientación la educación y los principios científicos, sin la cual los músculos obedecen, como en los hombres primitivos, sólo a la fuerza ciega del instinto». Pende, n. 35, p. 96.

37. El impulso al deporte competitivo fue en el fascismo posterior al estímulo a la educación física. El deporte competitivo y sus usos políticos tendrá una clara expresión en la creación de grandes estadios que desplazarían la inicial centralidad en el tema del Foro Mussolini.
} 
La importancia creciente de la ONB, justificaba monumentalizar su sede. El Foro Mussolini expresaba fielmente el propósito sincrónico de aunar tradición y modernidad a través de una obra que suscitaba el interés por el pasado sin dejar de remitir a la nueva sociedad que era su destinataria. La planta general denotaba fuertes rasgos clasicistas, a tono con las reminiscencias a una antigüedad mitológica que fluía en la arquitectura del Foro. El conjunto se completaba con la Academia Fascista de Educación Física, integrada por dos edificios simétricos conectados a través de un puente que enmarcaba el ingreso (Figura 3). Los rasgos más llamativos estaban en un estadio al que, por las 60 impactantes estatuas de mármol de Carrara de 5 metros de altura que lo circundaban y los grandes bloques de ese material que conformaron las graderías, se le dio el nombre de Stadio dei Marmi ${ }^{38}$. Allí quedaba expresada la nueva romanidad fascista, en un espacio para satisfacer las modernas exigencias del deporte y celebrar permanentemente la juventud y la raza itálica (Figuras 4 y 5 ).

El Foro incorporó luego dos verdaderos emblemas de la Roma mussoliniana que, a través del protagonismo absoluto del mármol, reforzaban las metafóricas alusiones de obras tan duraderas como el régimen que las hacía: se trataba de un gran obelisco con la inscripción Mussolini DUX y, unido a él a través de un eje visual, de la Fuente de la Esfera, un bloque de mármol de Carrara de tres metros de diámetro concebido como símbolo cósmico de perfección y de eternidad.

\section{Epifanía de la Roma Imperial: defensa de la raza y la exposición E42}

Con la proclamación del Imperio, Roma es la capital en el más estricto sentido etimológico: es la capitas requerida desde el corporativismo de la «biología política» para completar debidamente las funciones del organismo social.

Véase Teja, Ángela. Deporte y relaciones internacionales durante el fascismo en Italia. In: González Aja, Teresa, ed. Sport y autoritarismos. La utilización del deporte por el comunismo y el fascismo. Madrid: Alianza Editorial; 2002, p. 241-281.

38. Ricci, era de Carrara y poseía una gran pasión por las estatuas, además de ser Presidente del Consorcio del mármol de esa ciudad. Benton, n. 27, p. 126. 


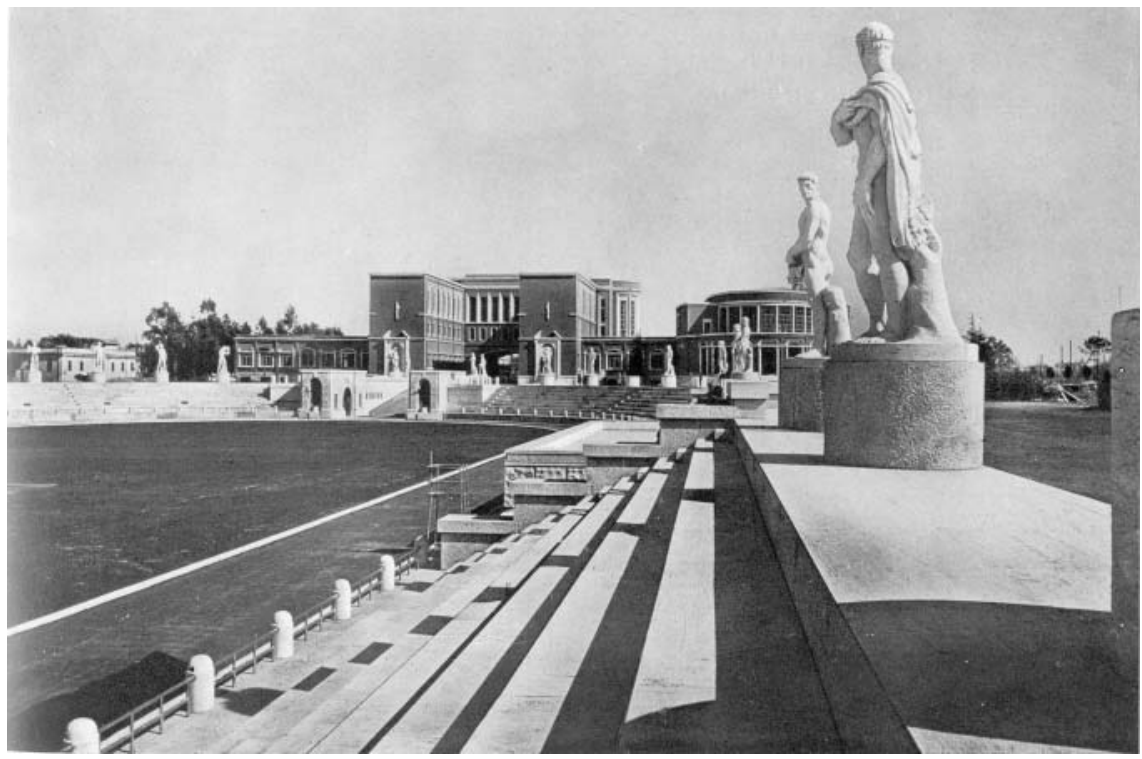

Figura 4. Stadio dei Marmi. Fuente: II «Foro Mussolini» in Roma. Rassegna di Archittetura. 1933; 7-8: $324-328$

La afirmación simbólica de Roma reposó también en la instalación de la «otredad» a partir de la conquista de Etiopía. La victoria permitía destacar la superioridad de la romanidad sobre las razas africanas, difundiendo este aserto a través de una intensa acción propagandística que incluyó al Instituto LUCE, y también a una parte importante del campo científico que cultivaba la «biología política». Las regiones conquistadas militarmente venían siendo objeto de distintos estudios, con expediciones científicas como la que 1905 encabezó Aldobrandino Mochi en Eritrea y treinta años después en las poblaciones negras de Somalia. Otras fueron las realizadas en Somalia por Stefanini y Paoli en 1913 y por Stefanini y Puccioni en 1924. A ellas se suman las emprendidas por Lidio Cipriani, director del Museo Fiorentino, en los años 1927 al 1933, y las que derivaron en los estudios de Guido Landra sobre la morfología de la cabeza en poblaciones africanas, destacados por Chiurco ${ }^{39}$.

39. Chiurco, Giorgio. La sanità delle razze nell'Impero Italiano. Roma: Istituto Facista dell'Africa Italiana; 1940, p. 742-743. 


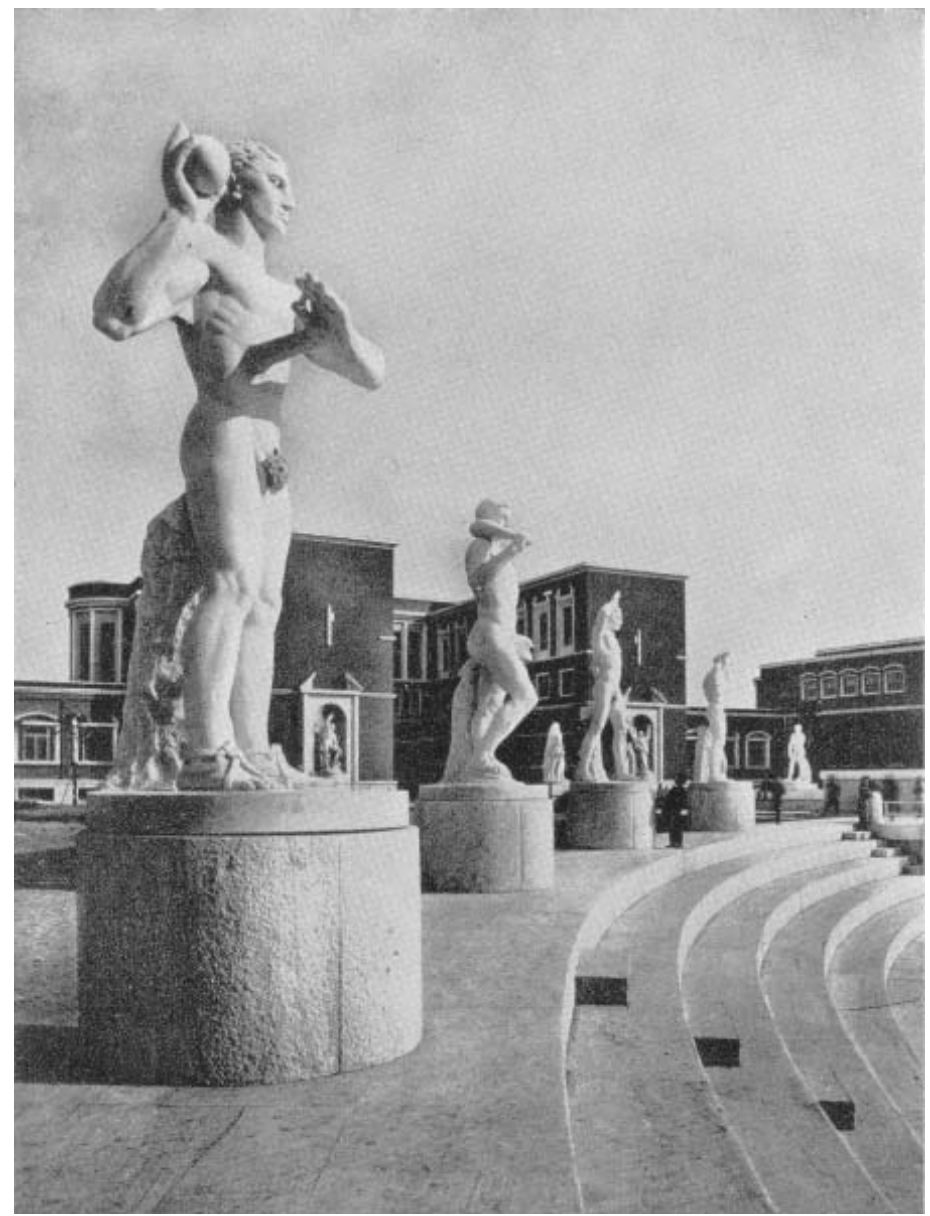

Figura 5. Estatuas del Stadio dei Marmi. Fuente: II «Foro Mussolini» in Roma. Rassegna di Archittetura. 1933; 7-8: 324-328.

La victoria militar aceleró el establecimiento de una legislación racial, que trascendió largamente la aspiración planteada en 1919 por GiuffridaRuggeri en el sentido de impedir uniones matrimoniales entre italianos y africanos. Racismo y ciudadanía se conjugaban en un sistema de premios y castigos asociados a la custodia de una entidad que debía quedar a salvo de aquello que podía provocar su decaimiento. La defensa de la romanidad requería así de una ciudadanía restrictiva, un régimen de apartheid, 
como quería Cipriani ${ }^{40}$. De abril de 1936 data una orden de rechazar los pedidos de adopción de etíopes de color por familias italianas y en junio de ese año se decretó que:

«a los nacidos en el África Oriental italiana con padres ignorados, no les sería reconocida la ciudadanía italiana cuando los caracteres somáticos y otros eventuales indicios no hagan pensar con fundamento que ambos progenitores fueran de raza blanca» ${ }^{41}$.

También en abril de 1936 comenzó a regir el impedimento matrimonial entre etíopes e italianos por motivos eugénicos y al año siguiente los mismos causales llevaron a acrecentar las penas por episodios de «promiscuidad entre blancos y negros». Todo ello era entendido por Alberto Chiurco (Profesor de la Universidad de Siena) como el establecimiento de «medidas destinadas a poner un freno al mestizaje respetando las leyes biológicas que presiden el orden social» ${ }^{42}$. Precisamente científicos como Chiurco y Cipriani habían contribuido a las medidas adoptadas por el Duce, a través de estudios de fotografía antropológica, antropología biométrica y de medicina, en los que ponían de manifiesto que la «la raza negra era refractaria a toda evolución intelectual» ${ }^{43}$ : su «inferioridad mental» estaba «determinísticamente ligada a condiciones biológicas originarias» y por esta razón era imposible modificar ${ }^{44}$. Pende también participó de estas ideas solicitando no perder de vista que en «la batalla de la raza» hacía falta obtener una pronta amalgama de «cuerpos y almas de las distintas regiones italianas» y condenar «la mezcla de nuestra sangre con la de los africanos», alertando sobre el mal que entrañaba la caridad por el peligro de elevar el número y calidad de los africanos «con métodos de excesivo idealismo y de excesiva sentimentalidad ${ }^{45}$.

Con la colonización del África Oriental, y la firme decisión de proteger y expandir la «estirpe romana», dio comienzo el propósito de extender los límites del Imperio proclamado por el Duce, como lo había hecho el anti-

40. Collotti, Enzo. I fascismo e gliebrei. Le leggirazziali in Italia. Bari: Laterza; 2003, p. 33.

41. Chiurco, n. 39, p. 1050.

42. Chiurco, n. 39, p. 1051-1052.

43. Collotti, n. 40, p. 33.

44. Collotti, n. 40, p. 31.

45. Reproducido en Cassata, Francesco. «La Difessa della razza». Politica, ideología e imagine del razzismo fascista. Torino: Einaudi; 2008, p. 42-43. 
guo Imperio Romano al controlar durante cinco siglos el Mare Nostrum. La siguiente aventura militar del Duce en pos de lograr ese objetivo, fue la que desplegó en la península ibérica, donde la contribución italiana a las fuerzas del General Franco resultaría decisiva para el desenlace que tuvo la Guerra Civil española. Mussolini aspiraba a hacer de España un satélite italiano, al punto de llegar a preverla dentro de su Imperio, bajo la conducción de un rey que imaginó en Amadeo de Saboya-Aosta (virrey de la Etiopía fascista) ${ }^{46}$.

El expansionismo mussoliniano, pronto encontraría sus límites y a la vez su complementariedad en el régimen de Adolf Hitler. Al interior de la propia Italia, la proclamación del Imperio acentuó el acercamiento de su política racial a la que venía siendo aplicada en Alemania. Y también desató una tensión entre afinidad y competencia interimperial con medidas como la presentación de la candidatura de Roma para organizar los Juegos Olímpicos de 1944. En vista a ese evento que tendría lugar en el Foro Mussolini, fue inaugurado el Palacio de las Armas que daba una muestra de la orientación perseguida en materia de militarización del deporte.

Precisamente el Foro Mussolini sería uno de los escenarios utilizados para exaltar los acuerdos celebrados entre Mussolini y Hitler en 1937. Luego de recibir a Mussolini en el Estadio Olímpico de Berlín, Hitler visitó Roma, donde se deslumbró con la arquitectura clásica monumental (lamentándose por carecer Alemania de edificios como el Coliseo o el Panteón), conoció la Muestra Augusta de la Romanidad ${ }^{47}$ y finalmente vivió una apoteósica jornada junto al Duce en el Stadio dei Marmi.

Y así como Speer planificaba, por encargo del Führer, la monumental Berlín de 1955, la Roma del nuevo Imperio mussoliniano también fue objeto de una cuidada puesta en escena a cargo de Marcello Piacentini que enfatizaría la voluntad de recuperar la hegemonía sobre el Mare Nostrum ${ }^{48}$. La Vía del Imperio, uniría a Roma con Ostia para indicar el sentido en el que debía orientarse el movimiento hacia la conquista de nuevos territorios

46. Véase Heiberg, Morten. Emperadores del Mediterráneo. Franco, Mussolini y la Guerra civil española. Barcelona: Crítica; 2003.

47. Mussolini dejó inaugurada la muestra antes de partir a Berlín, en el Palacio de las Bellas Artes, el mismo sitio donde en 1932 tuvo lugar la Muestra de la Revolución Fascista.

48. Las tareas que pasó a desempeñar Marcello Piacentini como arquitecto del régimen llegaron a considerarse como la contraparte italiana de las que cumplía Speer junto a Hitler. Véase Scarrocchia, Sandro. Albert Speer e Marcello Piacentini. L'architettura del totalitarismo negli anni trenta. Milano: Skira; 1999. 
y en esa dirección nacería otro nuevo emblema del fascismo. Se trataba de una exposición internacional con muestras efímeras y permanentes, dentro de una urbanización general que en 1937 comenzó a prepararse con vistas a 1942, cuando se esperaba celebrar el veintenio del ascenso de Mussolini al poder. Bautizada como E42 ${ }^{49}$, la exposición buscaba ir más allá de la exitosa Muestra de la Revolución Fascista habilitada para el decenio de la «Marcha sobre Roma». La E42 indicaría con su ubicación extraurbana la proyección del núcleo monumental romano-fascista del centro antiguo hacia el mar ${ }^{50}$ y en sus características materiales estaba llamada a expresar de manera elocuente la cultura y la ciencia de la nueva Roma Imperial.

La colosal intervención involucraba unas 400 hectáreas, organizadas a partir del eje de la Vía del Imperio. La E42 debía ser para Bottai la «Olimpíada de la civilidad», denotando el plano de comparación entablado con las Olimpíadas celebradas en 1936 en Berlín. Precisamente la idea surgió, cuando la perspectiva imperial inducía a magnificar todo emprendimiento, incluso el de Pende de crear en Roma la Superuniversidad del mundo latino.

La E42 representaba el genio bimilenario de Roma y la acción revolucionaria que dio comienzo en 1922 en esa ciudad y tendría a los Palacios del Congreso, de la Civilización, de las Fuerzas Armadas y a la plaza Imperial en su núcleo central. También sería una caja de resonancia del protagonismo asumido por la cuestión racial en el nuevo Imperio, y precisamente desde el inicio de las tareas organizativas, Pende y su ciencia tuvieron un lugar destacado. En efecto, el plan previó la instalación de un Museo de la Raza y una Muestra de la Ortogénesis Fascista de la Estirpe a cargo de Pende. La idea de Pende, era inaugurar un segundo instituto biotipológico que a la vez funcionara durante la exposición como una muestra de las acciones llevadas a cabo por el fascismo en materia de defensa social y defensa de la estirpe. El Duce se expidió favorablemente y tras requerir sólo la sustitución de la palabra «Estirpe» por «Raza», exaltó la importancia que esa iniciativa tendría al «demostrar al mundo entero cuanto más modernamente científicas son las cosas que hace el régimen por la bonificación de la raza». Así nacería el Instituto finalmente denominado de Bonificación Humana

49. Sobre la E42 se realizó en 1987 una notable exposición que dio origen a una obra de referencia con abundante información y textos muy sólidos: E42 Utopia e scenario del Regime. Roma: Cataloghi Marsilio; 1987. El volumen 1 fue coordinado por Gregory, Tullio y Tartaro, Achille; y el volumen 2 por Calvesi, Maurizio; Guidoni, Enrico y Lux, Simonetta.

50. Vallejo, n. 19, p. 238. 
y Ortogénesis de la Raza ${ }^{51}$, y concebido como uno de los edificios permanentes de la exposición, connotando con su presencia al sector en el que estaba inscripto y que llevó el nombre de Ciudad de la Ciencia.

En 1938 la cuestión racial se volvió más gravitante aún, luego de plantearse una problemática internacional en torno a los judíos que buscaban refugio fuera de Alemania. En julio de ese año el tema motivó la realización de una conferencia internacional convocada en la ciudad francesa de Evian por el presidente de los Estados Unidos, Franklin Delano Roosevelt. A pesar de reunir delegados de 32 países europeos y americanos, el encuentro fracasó. Y la nota más saliente fue la respuesta dada por Italia que, en concordancia con el cierre de la conferencia, lanzó una declaración aparecida el 14 de julio de 1938 con el título de «Il fascismo e i problema della razza», también conocida como «Manifiesto de la raza». Redactada por destacados científicos, consistía en una fundamentación de la necesidad de iniciar en Itala la persecución del judaísmo. El científico de mayor reconocimiento que participó en su elaboración, fue precisamente Pende. Junto a él participaron figuras que aquilataban una larga trayectoria dentro del racismo científico como Cipriani y Landra.

El «Manifiesto de la raza» sostenía que el racismo era una concepción netamente biológica. Además exaltaba que la raza italiana tenía un origen ario, y, en contraposición, endilgaba a los judíos conformar una raza europea no asimilable, concluyendo en que la pureza de la raza italiana no debía ser contaminada con razas inasimilables. En lo sucesivo el Estado se encargaría de plasmar estas ideas a través de leyes que, con el antecedente de las medidas adoptadas contra los africanos, se volvieron contra los judíos, especialmente atendiendo el peligro de «contaminación racial» ${ }^{52}$.

Así, tras la alianza política con Alemania, se tramaba un racismo que buscaba sus fundamentos científicos en la «biología política» y en una maleable definición de raza que, ante estas circunstancias, podía explicar el antisemitismo apelando a teorías ya enunciadas antes por el Conde De Gubernatis, Alfredo Nicéforo o Giuseppe Sergi. Asimismo, publicaciones como Difesa della raza, aparecida en agosto de 1938 bajo la dirección de Telesio Interlandi, reactualizaban el racismo científico integrando las ver-

51. Vallejo, n. 19, p. 240.

52. Véase Collotti, n. 40; Finzi. Roberto. L'Università italiana e le leggi antiebraiche. Roma: Riuniti; 2003. 
siones antiafricanas y antijudías para dar fuerte respaldo intelectual a la política racial del fascismo ${ }^{53}$.

Inmersa en estas coordenadas raciales la E42 tendrá en el Instituto de Pende a una de sus primeras obras inauguradas en 1938. El edificio era una fortaleza que simbolizaba el concepto «verdaderamente totalitario y fascista de la raza mussoliniana». Era una ciudadela protegida por cuatro torreones exteriores que simbolizaban con ese número los biotipos, y más específicamente

«los pilares basales sobre los cuales debe apoyarse la bonificación humana: tutela y preparación armónica de la mujer, tutela y preparación armónica de los trabajadores, prolificidad de la raza y conservación de la pureza» ${ }^{54}$.

Esta ciudadela asumía las connotaciones que el teórico del renacimiento, León Batista Alberti, le había dado como el sitio en el que el tirano ejercita sin control su poder sobre sus súbditos, de quienes también se protege. La ciudadela tenía entonces por fin defender y ofender, en este caso defender a «nuestra» raza y ofender a las otras ${ }^{55}$.

La ubicación central de una capilla completaba la fortaleza mussoliniana del culto a la raza, exaltando la integración de la Iglesia Católica a esta versión eugénica ${ }^{56}$.

El inicio de la Segunda Guerra Mundial interrumpiría los trabajos de la E42, el más ambicioso emprendimiento del régimen, quedando por años abandonado tras alcanzar una parcial concreción.

\section{Principio del fin: «los italianos no son romanos»}

Las derrotas militares en la Segunda Guerra Mundial, precipitarían el desenlace del fascismo, con la nación sumida en una grave crisis. Si romanizar

53. Difesa della Razza contó con colaboraciones de científicos participantes en la elaboración del «Manifiesto de la raza» como Cipriani, Landra y el propio Pende. Cassata, n. 45.

54. Noccioli, Marco. Istituto dell'Ortogenesi. In: Calvesi, Maurizio; Guidoni, Enrico; Lux, Simonetta, eds. E42 Utopia e scenario del Regime. Tomo 2: Urbanistica, architettura, arte e decorazione. Roma: Cataloghi Marsilio; 1987, p. 506-508 (508).

55. Vallejo, n. 19, p. 262.

56. La revista Civiltà Cattolica expondrá las grandes afinidades existentes entre la doctrina de la ortogénesis y las enseñanzas de la Iglesia Católica, exaltando «la originalidad y el genio de las teorías de Pende». Cassata, n. 16, p. 211. 
era afirmar los valores de una raza y una estirpe milenaria, el fracaso del régimen que llevaba a cabo esta certeza sólo podía obedecer, en palabras del Duce, a la decepcionante constatación de que el papel atribuido a las nuevas instituciones y los simbólicos escenarios urbanos no había sido suficiente: «los italianos no son romanos» dirá lacónicamente ${ }^{57}$.

La reflexión del Duce encerraba una interpelación a los mecanismos capaces de proteger y a la vez expandir su raza. Esa lábil formulación que permitía desplazar un inherente determinismo desde lo biológico a lo ambiental, había posibilitado al fascismo crear su propia noción de raza y estirpe, en unos casos como resultado de una herencia milenaria, en otros como un disciplinamiento operado a través de la cultura, romanizando pueblos.

Dentro de ese racismo, el antisemitismo, llegaría en una etapa tardía del régimen pero en modo alguno suponía un cambio radical en la política fascista. Vale decir, el fascismo se expandió con la misma fuerza que el racismo científico, que le había dado buena parte de su sustento y que una vez desatado se canalizaba a través de distintas formas de identificar el universo de la otredad. Si desde un principio quedaba en claro que lo africano constituía la más clara contracara racial de la romanidad que debía ser custodiada de los riesgos de «contaminación», el antisemitismo explícito aparecerá cuando la otredad denostada asumía la forma del judío que quería escapar de Alemania y amenazaba con invadir Italia trayendo consigo el liberalismo, el comunismo y demás «bacilos» modernos.

Siendo el racismo un mecanismo que se vale de las estructuras de poder para hacer más vulnerables a grupos que representan una amenaza para quienes reúnen los valores que se pretenden proteger, quedaba claro que el camino ya estaba trazado al momento de producirse la proclamación del Imperio. Y que éste, en todo caso, vino a profundizarlo. La eugenesia y la «biología política» eran factores inherentes al régimen y después de que en la primera posguerra identificara el mal en el «otro» africano, inferiorizado científicamente antes de ser luego colonizado, expoliado y sometido militarmente por un Imperio en el que carecería de los derechos que sí poseían aquellos que representaban un valor para la raza, sobrevenían medidas similares contra los judíos. Se trataba de un proceso que en materia racial trazaba claramente una línea de continuidad, aun cuando 
resulte menos frecuente advertirla en miradas históricas que se detuvieron en enfatizar la drástica irrupción del racismo y el antisemitismo producida en el fascismo como consecuencia del acuerdo sellado por Mussolini con Hitler en 1937. 


\section{Rome: capital of an empire under the banner of political biology (1936-1942)}

Gustavo Vallejo ..........................................

1.- Rome between social defence and defence of the race. 2.-From the «bad life» to "political biology». 3.- Ancient Rome and the new fascist Italy. 4.Epiphany of Imperial Rome: defence of the race and the E42 exhibition. 5.Beginning of the end: «Italians are not Romans».

ABSTRACT: This paper analyzes the symbolic conformation of Rome and Romanism as important factors in the affirmation of the power of fascism, especially after the proclamation of the Empire in 1936. Within this framework, it explores the role of science in legitimizing the direct correlation of this symbolic universe with a praxis that exalted racial superiority inherited from Ancient Rome. It investigates the links between the eugenic discourse and the exercise of power behind the "biology policy», including fascist organicism and racism. In fact, Rome was the essence of an empire that was reborn after fifteen centuries and, between its historical legacy and the new scenarios created by fascism for disciplining the population, Romanism had to condense all of the merits of the race, encouraging military conquests and promoting responsibility for maintaining racial purity and avoiding «unwanted miscegenation» with conquered peoples. The idea of Romanism also encouraged a continuation of the persecution of Jews started in Germany. Hence, science ratified a widespread idea of the Romanization as a crusade to impose a force, exaggerated on racial grounds, which integrated confidence in environmental factors with a crude biological determinism. 